\title{
Using Gagne's instructional model in phlebotomy education
}

This article was published in the following Dove Press journal:

Advances in Medical Education and Practice

3I August 2016

Number of times this article has been viewed

\section{Wee Hong Woo \\ School of Chemical \& Life Sciences, Singapore Polytechnic, Singapore}

Correspondence: Wee Hong Woo School of Chemical \& Life Sciences, Singapore Polytechnic, 500 Dover Road, Singapore 13965 I

Tel $+656772 \quad$ I899

Fax +6567721976

Email whwoo@sp.edu.sg
Abstract: As the role of a phlebotomist in a clinical setting involves patient interactions, correct patient identification, and blood specimen accessioning, it is essential that the phlebotomy education pay attention to these procedural tasks to inculcate a culture of patient safety. Using the Gagne's nine events of instruction as the basis of teaching model, this paper describes the lesson plan for teaching the topic of patient approach to a group of phlebotomy students without prior clinical experience.

Keywords: venipuncture, Gagne's model, instructional design, patient handling, Peyton's steps

\section{Introduction}

In polytechnic, teaching a group of phlebotomy students without clinical experiences, the topic of "approaching the patient; the role of a phlebotomist" is challenging, yet fulfilling. The challenging part is to ensure the learners are able to comprehend the implications of patient safety taught in the topic and apply what they have learnt. If the learners demonstrate the desired clinical skills, the sense of fulfillment is realized.

Gagne's instructional model ${ }^{1}$ has been used widely to teach procedural skills..$^{2-5}$ As Robert Gagne has categorized the five learning outcomes as intellectual skills, verbal information, cognitive strategies, attitudes, and motor skills, the Gagne's nine events of instruction (Table 1) provide an instructional framework to achieve these outcomes. Consequently, I deliberated on the contextualization process of Gagne's events of instruction in phlebotomy education, and describe here the lesson plan for the topic of approaching the patient.

\section{Prerequisites}

It is necessary that the learners have prior knowledge about the topic of preanalytical variables. Preanalytical variables refer to those factors that are associated with the pre-examination phase of the clinical laboratory testing process. ${ }^{6}$ Generally, preanalytical variables can be categorized into patient variables, variables in blood collection technique, transportation variables, and specimen variables. Table 2 presents a myriad of preanalytical variables that are related to blood specimen collection. As these variables address the quality of the blood specimens collected in a clinical setting, knowledge of these variables forms the prerequisite for the lesson. Usually, a separate lesson is required to address this topic in its entirety.

To highlight some of the preanalytical variables listed in Table 2, the role play activity (Table 3) is employed to set focus on patient variables (fasting), variables of 
Table I Gagne's nine events of instruction

\begin{tabular}{ll}
\hline Instructional event & Cognitive process \\
\hline I. Gaining attention & Reception \\
2. Informing learner of objectives & Expectancy \\
3. Stimulate recall of prior learning & Retrieval \\
4. Presenting stimulus & Selective perception \\
5. Providing learning guidance & Semantic encoding \\
6. Eliciting performance & Responding \\
7. Providing feedback & Reinforcement \\
8. Assessing performance & Retrieval \\
9. Enhancing retention and transfer & Generalization
\end{tabular}

Note: Adapted from Gagne RM, Wager WW, Golas KG, Keller JM. Principles of Instructional Design. 5th ed. (C) 2005 South-Western, a part of Cengage Learning, Inc. ISBN: 9780534582845 (0534582842).'

Table 2 The preanalytical variables associated with blood specimen collection

\begin{tabular}{llll}
\hline $\begin{array}{l}\text { Patient } \\
\text { variables }\end{array}$ & $\begin{array}{l}\text { Variables in } \\
\text { technique }\end{array}$ & $\begin{array}{l}\text { Transportation } \\
\text { variables }\end{array}$ & $\begin{array}{l}\text { Specimen } \\
\text { variables }\end{array}$ \\
\hline Age & Patient & $\begin{array}{l}\text { Delivery (by hand, } \\
\text { Pneumatic tube) }\end{array}$ & $\begin{array}{l}\text { Identification } \\
\text { and labeling }\end{array}$ \\
Sex & identification & Temperature/light & $\begin{array}{l}\text { Equipment/ } \\
\text { supplies }\end{array}$ \\
Diet & Tourniquet & Timing & Anticoagulants \\
Smoking & application & Site selection & Specimen \\
Drugs/alcohol & Decontamination & & processing \\
Exercise & Equipment/supplies & & (centrifugation) \\
Stress & & & Storage prior to \\
Diurnal/circadian & & & testing \\
variations & & & \\
Altitude & & & \\
Dehydration & & & \\
\hline
\end{tabular}

Notes: Adapted from Garza, Diana; Becan-McBride, Kathleen, Phlebotomy Handbook, 9th, () 2015. Adapted by permission of Pearson Education, Inc., New York, New York. ${ }^{23}$ Data from McCall and Tankersley. ${ }^{24}$ technique (patient identification), transportation variables (pneumatic tube), and specimen variables (specimen labeling). Learners need to pay attention to the requirement of a fasting blood sample and should be able to pick up the wrongly typed patient name on the laboratory requisition form. Hence, the intent of such a role-play activity is to train the learners to take a conscientious effort in ensuring quality blood collection. Such procedural tasks, although cumbersome, are highly recommended, as it reduces errors related to patient identity. ${ }^{7}$ Conversely, learners are also encouraged to ponder upon the consequences of a nonfasting lipid test result. Learners need to point out that a nonfasting lipid test result misinterpreted as a fasting one could possibly lead to a patient being put on an aggressive course of statin therapy unnecessarily or subject a patient to an unwittingly adjusted dosage of an ongoing statin without the evidence of a reliable blood test result.

A lesson plan for the topic was developed using the Gagne's nine events of instruction ${ }^{1}$ and each of the events is described in the following sections.

\section{Contextualizing Gagne's nine events of instruction Gaining attention}

To engage learners at the beginning of a lesson, I call for their attention to watch a poignant video that shows how a simple blood test can make a big difference to a person's

Table 3 Role-play scenario

\begin{tabular}{|c|c|}
\hline Place: & The phlebotomy room in a medical laboratory \\
\hline Characters: & I) Phlebotomist, 2) adult patient; Ms Tan Lee Lee (or) Mr Tan Sin How \\
\hline \multirow[t]{3}{*}{ Equipment: } & Two chairs and a table \\
\hline & Prelabeled laboratory requisition form \\
\hline & Unlabeled prefilled blood tubes \\
\hline \multirow[t]{8}{*}{ Background: } & The medical laboratory is a facility that analyses clinical specimens for the purpose of health and disease management. Blood is a body \\
\hline & fluid that is commonly used for such investigational purposes. Upon the order of a medical doctor, the patient will turn up at the medical \\
\hline & laboratory with the prefilled laboratory requisition form for the blood tests. It is the role of the phlebotomist to ensure correct patient \\
\hline & identification and rightful specimen collection, while paying attention to the quality of specimen collected. \\
\hline & Depending on the role-play pair, the adult patient can be a female (Ms Tan Lee Lee) or a male (Mr Tan Sin How). Adult patients are told \\
\hline & what their names are and they are to carry the stapled prelabeled laboratory form to the phlebotomist. The laboratory requisition form is \\
\hline & purposely labeled wrongly as Ms Tan Lily or Mr Tan Sing Howe. All other patient identifiers remain correct. As lipid profile is ordered, a \\
\hline & fasting status is required. Fasting is defined as no caloric intake for at least 8 hours. \\
\hline Scenario: & An adult patient has been scheduled to go for a blood test. Holding a prelabeled laboratory requisition form, the patient enters the medical \\
\hline & laboratory and requests for the blood testing service. The patient is directed to the phlebotomy room by the counter receptionist. You are \\
\hline & a phlebotomist and you are going to approach the patient. \\
\hline \multirow[t]{4}{*}{ Objectives: } & - To uphold the positive first impression of a professional phlebotomist \\
\hline & - To ensure positive patient identity (using two unique patient identifiers) \\
\hline & - To ensure proper blood specimen identification (labeling) \\
\hline & - To ensure quality of blood specimen collected (mindful of preanalytical variables; fasting) \\
\hline The student & - Greet patient with a smiling face and in a friendly tone, and maintain comfortable eye contact \\
\hline \multirow[t]{4}{*}{ should: } & - Identify the patient by using at least two unique patient identifiers (eg, name [to spell out] and NRIC number) \\
\hline & - Check the status of dietary restriction (fasting; "Have you taken any food or drink for the past 8 hours?") \\
\hline & - Label the blood tube immediately after blood collection using simulated prefilled blood tube \\
\hline & - Send the labeled blood tube to the laboratory using mock pneumatic tube \\
\hline
\end{tabular}

Abbreviation: NRIC, National Registry Identification Card. 
life (first 1 minute 31 seconds; https://www.youtube.com/ watch? $\mathrm{v}=\mathrm{Ph} 4 \mathrm{H} 1 \mathrm{AuvOH} 0$ ). This video is used to capture the attention of visual and auditory learners. ${ }^{8}$ Furthermore, the sadness associated with a widow reminiscing about her late husband would engage the learners emotionally and trigger them to be more conscientious in proper blood collection procedures, and thus be more ready to learn. ${ }^{9}$

I am mindful that a poignant video may trigger previous bad experiences. In such cases, rather than to dwell into the negativities of bad experiences, staying focused on the learning the objectives and being positive toward a safer and better health care is a preferred option..$^{10,11}$

\section{Informing learner of objectives}

Immediately after the video, I will move on to state the lesson objectives. This helps in preparing the learners for the imminent learning process and establishing the learners' achievable expectations for the lesson. To maintain the learners' interest, I will relate the importance of the objectives to the video just seen, so that the learners can appreciate them in real-world contexts. Such practice concurs with the law of intensity. ${ }^{10}$ For this lesson, the objectives are presented as:

Upon completing this lesson, you will be able to:

- state three ways to uphold the positive first impression of a professional phlebotomist;

- list four general criteria for a quality blood collection;

- perform positive patient identification;

- perform proper blood specimen identification.

\section{Stimulate recall of prior learning}

The constructivism theory put forth that the learning process is facilitated if prior knowledge and personal experience can be associated with new information. ${ }^{12}$ Hence, it is necessary to stimulate recall of prior learning. Yet, for this lesson, the learners have no relevant clinical experience in handling patients. To overcome this, the learners will be asked to recall their recent experience in getting a hepatitis B blood test done while I project a picture of a mock hepatitis B report on the projector screen. Here, the learners are placed on the receiving end and they could comment on the standard of service they received as patients. With questions like, "Did the clinical staff handle the whole procedure with professionalism?" If yes, "What were the professional behaviors?" If no, "What was lacking?", and, "What would you do differently if you were the clinical staff?". The learners are triggered to ponder on the procedures, deliberating on how to make a difference from a personal perspective. This thinking and sharing process appeals to visual and auditory learners, ${ }^{8}$ and engages linguistic, intrapersonal, and interpersonal intelligences. $^{13}$

After spending approximately 5 minutes on recalling, I will move on to deliver my presentation. The intent is not to drag the recalling phase so long that the learners lose focus and interests.

\section{Presenting stimulus}

Here, I will deliver my content using PowerPoint presentation. There are four topics, namely:

- positive first impression;

- ensure quality of blood specimen collected;

- positive patient identification;

- proper blood specimen identification.

Each topic is covered in two to three slides. Pictures and topical tabulated checklists are included to help the learners to learn in "chunks" and help them to assimilate the new information. ${ }^{14,15}$ To engage the learners, I encourage them to recall the service they received for the hepatitis B blood test and try using the checklist designed for positive first impression and positive patient identification. This process engages their linguistic and intrapersonal intelligences ${ }^{13}$ and appeals to visual, auditory, and kinesthetic styles of learners. ${ }^{8}$ In addition, I endeavor to deliver the content in a lively and enthusiastic manner, as this will influence the learners to learn positively. ${ }^{16}$

\section{Providing learning guidance}

There is a saying that goes, "first impressions last." Hence, the first rightful demonstration with step-by-step explanation is a good starting point for learning. This practice concurs with the law of primacy ${ }^{10}$ and the first step in the Peyton's fourstep approach to teaching (demonstration-deconstructioncomprehension-performance). ${ }^{17}$ To begin, I "demonstrate" how I approach the patient politely, identify the patient correctly, label the blood tubes rightfully and dispatch the blood tubes in a timely manner. Next, I "deconstruct" the patient approach by explaining the rationale for each step taken, and encourage the learners to ask questions for better "comprehension." This process engages the learners' linguistic, kinesthetic, and interpersonal intelligence, ${ }^{13}$ and stimulates the reflectors to ponder. ${ }^{18}$ Furthermore, the read/ write style of learners ${ }^{8}$ can be engaged by encouraging them to jot down notes for future references.

To demonstrate effectively, I have to position myself before the whole class and ensure all learners can hear and see me and my "patient" before I begin. 


\section{Eliciting performance}

In this session, learners are grouped in small groups to practice the skill of approaching the patient via the role-play activity. I have chosen the role-play activity because it can simulate actual work conditions and has its focus on communication and affective interaction. ${ }^{19} \mathrm{~A}$ detailed scenario
(Table 3) has to be written purposefully to accommodate the learning objectives of the lesson. Learners need to understand the purpose of the role-play activity and hence time is needed to prepare them adequately. Learners are told to take turns to "perform" as a phlebotomist, a patient, and an observer (the fourth step in the Peyton's four-step approach). An observer

\section{Phlebotomy competency assessment}

\section{Approaching the patient}

Competency: Demonstrate proper patient identification and specimen identification.

Behavior:

Patient identification

Specimen identification

Patient care/customer service

\begin{tabular}{|c|c|c|c|c|c|}
\hline \multicolumn{2}{|c|}{ Procedures } & \multirow{2}{*}{$\begin{array}{l}\text { Satisfactory } \\
\text { performance } \\
5\end{array}$} & \multirow{2}{*}{$\begin{array}{l}\text { Improvement } \\
\text { needed } \\
3\end{array}$} & \multirow{2}{*}{$\begin{array}{c}\text { Unsatisfactory } \\
\text { performance } \\
0\end{array}$} & \multirow[t]{2}{*}{ Remarks } \\
\hline 1 & Greets patient and introduces self & & & & \\
\hline 2 & Checks requisition for all pertinent information & & & & \\
\hline 3 & Identifies patient correctly using two identifiers & & & & \\
\hline 4 & Washes hands & & & & \\
\hline 5 & Explains procedure to patient & & & & \\
\hline 6 & Checks for diet restriction and latex allergies & & & & \\
\hline 7 & $\begin{array}{l}\text { Selects correct tubes and equipment for } \\
\text { procedure }\end{array}$ & & & & \\
\hline 8 & Assembles equipment & & & & \\
\hline 9 & Notifies patient of the imminent puncture & & & & \\
\hline 10 & $\begin{array}{l}\text { Performs venipuncture procedure } \\
\text { (not done) }\end{array}$ & & & & \\
\hline 11 & Labels specimen properly & & & & \\
\hline 12 & $\begin{array}{l}\text { Checks puncture site when procedure is } \\
\text { complete }\end{array}$ & & & & \\
\hline 13 & Thanks and releases patient & & & & \\
\hline \multirow[t]{3}{*}{14} & Transports specimen to laboratory & & & & \\
\hline & Total points for each category: & & & & \\
\hline & Total of all categories: & \multicolumn{4}{|c|}{$/ 65$} \\
\hline
\end{tabular}


is encouraged to share or discuss with the performing "phlebotomist" on what was done well and what needs to be improved. Such activity engages the students' linguistic, kinesthetic, intrapersonal, and interpersonal intelligence, ${ }^{13}$ and stimulates the activists and pragmatists to act. ${ }^{18}$

It is important to encourage all learners to play a participative role. As mentioned, adequate preparation time is needed for role-play activity to be fruitful and meaningful. ${ }^{20}$

\section{Providing feedback}

As the learners are practicing in their role-play, I observe them closely and provide immediate feedback if they have done well or have missed out certain issues, such as inquiring good arms for venipuncture, checking for dietary restriction, labeling of blood tubes, and thanking the patient. Timely feedback is essential for good learning processes and for instilling good clinical practices. ${ }^{16,21}$ A conscientious effort must be made for this timely feedback. Additionally, to encourage the observers, feedback from the observers can be incorporated accordingly. ${ }^{19}$

\section{Assessing performance}

Once the learners are ready to demonstrate the approaching skills without prompt, I assess the learners in pairs, each take turns to be a phlebotomist and a patient. I will observe how a phlebotomist approaches the patient in a polite manner and accomplishes all required tasks. The assessment will be objectively done using a checklist (Figure 1). Learners can keep the graded checklist for their learning record and this will stimulate the theorists to analyze and the reflectors to ponder upon their assessed skills. ${ }^{18}$

\section{Enhancing retention and transfer}

As mentioned, learners are able to keep the graded checklist for their learning record. I encourage them to annotate on their graded checklist what they have done well and what needs to be improved. In this way, it helps them to retain the good practices that they have demonstrated. Furthermore, by allowing learners to share among themselves their learning achievements, learners learn collaboratively and transfer the skills into clinical practices when they are out for their clinical practicum. Such practices engage learners' linguistics, intrapersonal, and interpersonal intelligence, ${ }^{13}$ and concurs with the law of recency. ${ }^{10}$

At the end of the lesson, a lesson summary bullet pointing the learning objectives that has been covered is given. I will also allocate some time to clarify any doubts that the learners may have.

\section{Conclusion}

The Gagne's instructional model is a systematic approach to learning and its usefulness has been advocated in medical and nursing education. ${ }^{2,22}$ Using the Gagne's nine events of instruction, it caters to the different learning styles of learners and facilitates the learning processes of learners. To maximize its usefulness, the lesson plan can be contextualized to the other topics of phlebotomy like venipuncture and capillary puncture.

\section{Disclosure}

The author reports no conflicts of interest in this work.

\section{References}

1. Gagne RM, Wager WW, Golas KG, Keller JM. Principles of Instructional Design. 5th ed. Mason, OH: South-Western; 2005.

2. Belfield J. Using Gagne's theory to teach chest X-ray interpretation. Clin Teach. 2010;7(1):5-8

3. Khadjooi K, Rostami K, Ishaq S. How to use Gagne's model of instructional design in teaching psychomotor skills. Gastroenterol Hepatol Bed Bench. 2011;4(3):116-119.

4. Buscombe C. Using Gagne's theory to teach procedural skills. Clin Teac. 2013;10(5):302-307.

5. Ng JY. Combining Peyton's four-step approach and Gagne's instructional model in teaching slit-lamp examination. Perspect Med Educ. 2014;3(6):480-485.

6. Hawkins R. Managing the pre- and post-analytical phases of the total testing process. Ann Lab Med. 2012;32(1):5-16.

7. WHO. WHO Guidelines on Drawing Blood: Best Practices in Phlebotomy. Geneva: World Health Organization; 2010.

8. Fleming ND, Mills C. Not another inventory, rather a catalyst for reflection. To Improve the Academy. 1992;11:137-155. Available from: http:// digitalcommons.unl.edu/cgi/viewcontent.cgi?article $=1245 \&$ context $=p$ odimproveacad. Accessed September 26, 2015.

9. Knowles MS. The Adult Learner. A Neglected Species. Houston: Gulf Publishing; 1973. Available from: http://files.eric.ed.gov/fulltext/ ED084368.pdf. Accessed October 28, 2015.

10. Thorndike EL. The Fundamentals of Learning. New York: Teachers College Press; 1932

11. Braungart MM, Braungart RG, Gramet P. Applying learning theories to healthcare practice. In: Bastabel S, Gramet P, Jacobs K, Sopczyk DL, editors. Health Professional as Educator. Sudbury, MA: Jones \& Bartlett Learning; 2011.

12. Merrill MD. Constructivism and instructional design. Educ Technol Soc. 1991;31(5):45-53.

13. Gardner H. Intelligence Reframed: Multiple Intelligences for the 21st Century. New York: Basic Books; 1999.

14. Young JQ, Van Merrienboer J, Durning S, Ten Cate O. Cognitive load theory: implications for medical education: AMEE Guide No. 86. Med Teach. 2014;36(5):371-384

15. Sweller J. Cognitive load theory, learning difficulty, and instructional design. Learn Instr. 1994;4(4):295-312.

16. Sutkin G, Wagner E, Harris I, Schiffer R. What makes a good clinical teacher in medicine? A review of the literature. Acad Med. 2008;83(5): 452-466.

17. Nikendei C, Huber J, Stiepak J, et al. Modification of Peyton's four-step approach for small group teaching - a descriptive study. BMC Med Educ. 2014;14:68.

18. Honey P, Mumford A. Using Your Learning Styles. Maidenhead, UK: Peter Honey Publications; 1986. 
19. Nestel D, Tierney T. Role-play for medical students learning about communication: guidelines for maximising benefits. BMC Med Educ. 2007;7:3.

20. Joyner B, Young L. Teaching medical students using role play: twelve tips for successful role plays. Med Teach. 2006;28(3):225-229.

21. Ramani S, Krackov SK. Twelve tips for giving feedback effectively in the clinical environment. Med Teach. 2012;34(10):787-791.
22. Miner A, Mallow J, Theeke L, Barnes E. Using Gagne's 9 events of instruction to enhance student performance and course evaluations in undergraduate nursing course. Nurse Educ. 2015;40(3):152-154.

23. Garza D, Becan-McBride K. Phlebotomy Handbook: Blood Specimen Collection from Basis to Advanced. Upper Saddle River NJ: Pearson Education, Inc; 2015.

24. McCall RE, Tankersley CM. Phlebotomy Essentials. Philadelphia: Wolters Kluwer; 2016.

\section{Publish your work in this journal}

Advances in Medical Education and Practice is an international, peerreviewed, open access journal that aims to present and publish research on Medical Education covering medical, dental, nursing and allied health care professional education. The journal covers undergraduate education, postgraduate training and continuing medical education including emerging trends and innovative models linking education, research, and health care services. The manuscript management system is completely online and includes a very quick and fair peer-review system. Visit http://www.dovepress.com/testimonials.php to read real quotes from published authors.

Submit your manuscript here: http://www.dovepress.com/advances-in-medical-education-and-practice-journal 